\section{SPSA Calls for Proposals}

The Southern Political Science Association (SPSA) is now accepting submissions for the 2014 Conference. SPSA invites anyone interested in attending the 2014 Conference in New Orleans to look at the 2014 Call for Proposals. Conference dates are January 9-11, 2014, at the Hyatt Regency in New Orleans, Louisiana.

If you are interested in presenting your research at the 2014 Conference in New Orleans, Louisiana, please upload an abstract to our submission site, All Academic. You will need to create a new profile for All Academic, even if you have used this site for other meetings. The deadline for abstract upload is August 16, 2013.

\section{Comparative Democratic Theory Workshop Offered}

Texas A \& M University TAMU/ TAMU Qatar Comparative Political Theory Program hosts the Comparative Democratic Theory Workshop, October 11 and 12, 2013. The workshop explores, in comparative perspective, the meanings, prospects, and problems of democracy in intellectual traditions outside Western Europe and the United States. The aim is to have inter-cultural crossfertilization of ideas with respect to theories of democracy.

There will be panels on democracy in relation to representation, race/ethnicity, religion, and power/inequality.

Participants: Will Kymicka (Queen's), Nancy Rosenblum (Harvard), Nadia Urbinati (Columbia), Joshua Mitchell (Georgetown), Leonardo Avritzer (Minas Gerais, Brazil), Enrique Peruzzotti (Di Tella, Argentina), Lawrence Hamilton (University of Johannesburg, South Africa), Ajume Wingo (University of Colorado/Cameroon), Leigh Jenco (LSE), Sor Hoon Tan (National University of Singapore), Karuna Mantena (Yale), Andrew March (Yale), Hassan Bashir (TAMU Qatar), Phil Gray (TAMU Qatar), Nura Hossainzadeh (Berkeley), Peter Rutland (Wesleyan), Anne Norton (University of Pennsylvania), and Michael Walzer (IAS).

Send all inquiries to the Organizer, Professor Diego von Vacano, Political Science, Texas A\&M University, at davacano@pols.tamu.edu.

\section{Call for Nominations}

The Council for European Studies (CES) is calling for nominations for its 2014 European Studies First Article Prize competition. This Prize honors the best early work of the next generation of European Studies scholars. Two prizes will be awarded in 2014: one in the Humanities and one in the Social Sciences. The deadline for nominations is February 24, 2014.

Each prize winner will receive $\$ 500$ and public recognition on the Council's website. PhD advisors, journal editors, and editorial board members are strongly encouraged to nominate promising candidates. Individuals may nominate themselves without prejudice. To nominate a candidate for the prize, and learn more, use the nomination form located on their website Coucilfoeuropeanstudies.org/ grants-and-awards. 